\title{
Leaders Exhibiting High Emotional Intelligence Are More Dedicated to Their Job Performance
}

\author{
Donnisha Beverly ${ }^{1}$, James A. Williams ${ }^{2}$, Miranda Kitterlin ${ }^{3}$ \\ ${ }^{1}$ College of Business, University of Phoenix, Washington, USA \\ ${ }^{2}$ School of Hospitality, Sport, and Recreation Management, James Madison University, Harrisonburg, USA \\ ${ }^{3}$ Chaplin School of Hospitality and Tourism Management, Florida International University, North Miami, USA \\ Email: grafixdzyner@comcast.net, will22ja@jmu.edu,mkitterl@fiu.edu
}

Received October $17^{\text {th }}, 2012$; revised November $20^{\text {th }}, 2012$; accepted November $29^{\text {th }}, 2012$

\begin{abstract}
The purpose of this study was to identify the effect of information technology leaders' emotional intelligence on subordinate job performance. Participants consisted of information technology leaders, and were recruited from the Association for Information Technology Professionals (AITP) and the Information Technology (IT) Specialist group in LinkedIn (a business-oriented network website). A quantitative, correlational approach was taken by an online administration of two validated instruments - the Emotional Quotient Inventory (EQ-i) and Van Scotter and Motowidlo's measures for contextual performance (interpersonal facilitation and job dedication). Findings indicated that there was a positive relationship between IT leaders' emotional intelligence scores and subordinates' job performance ratings. Specifically, higher IT leaders' general mood scores, and optimism scores are associated with subordinates' higher interpersonal facilitation and job dedication scores. Further, results provided insight on IT leaders' EI training needs, career development, and guidelines for areas of improvement.
\end{abstract}

Keywords: Technology Managers; Emotional Intelligence; LinkedIn; EQ-i; Job Performance

\section{Introduction}

It has been suggested that emotional intelligence (EI) can be of interest to organizational researches only if EI can be related to an organizational outcome, such as job performance (Law, Wong, Huang, \& Li, 2008). Still, academic investigation relating EI to organizational outcomes are scarce (Côté \& Miners, 2006; Law, Wong, Huang, \& Li, 2008; Wong \& Law, 2002). Despite the growing amount of literature on EI, the relationship between emotional intelligence and job performance is highly understudied (Côté \& Miners, 2006; Law, Wong, Huang, \& Li, 2008; Wong \& Law, 2002). Within the minimal amount of EI and job performance literature, researchers found evidence of an existing relationship between individual emotional intelligence (EI) and job performance (Côte \& Miners, 2006; Daus \& Ashkanasy, 2005; Law et al., 2008). Yet, previous research has failed to adequately assess how leader emotional intelligence impacts subordinate job performance (Wong \& Law, 2002). Thus, the focus of this study was to address the existing literature gap concerning the effect of leader EI on subordinate job performance.

Literature on emotional intelligence (EI) in the workplace has flourished since the 1995 publication of Goleman's bestselling novel, Emotional Intelligence (Johnson, 2005). In 2010, the Internet-based book retailer Amazon listed more than 15,000 titles devoted to the topic of EI (Amazon, 2010a). Research linking EI to leadership effectiveness proposed that EI could positively or negatively affect subordinates' perceptions of the leader, thus affecting job performance (Fambrough \& Hart, 2008). Given these previous findings, the current project aimed to address the existing literature gap by examining leader emotional intelligence with subordinate job performance ratings, specifically in the Information Technology (IT) industry sector.
The independent variable for this study was IT leaders' emotional intelligence scores, with the dependent variable being subordinate contextual job performance ratings. This approach was taken in order to gain a better understanding of how leader emotional intelligence impacts subordinates job performance. In addition to contributing to the growing body of knowledge concerning EI, findings may lead to further explanatory studies on EI's impact on subordinate job performance factors.

\section{Literature Review}

The relationship between leader emotional intelligence and subordinate job performance is widely understudied (Côté \& Miners, 2006; Daus \& Ashkanasy, 2005; Law et al., 2008; Wong \& Law, 2002). There is no noted or plausible research conducted to insinuate a correlational relationship between emotional intelligence and job performance ratings in the information technology field. Research performed by Caruso and Gentry (2005) suggested that the primary causes for IT leadership failure involved emotional intelligence, and included a lack of empathy, a lack of emotional ability, and an inability to connect with others.

\section{Emotional Intelligence and Leaders}

Results of previous research suggested that emotions and moods could have a strong impact on decision-making effectiveness. Cooper's (1997) study on leaders' emotions concluded that proper management of emotions could elicit follower trust, commitment, and loyalty, as well as innovation, productivity gain, and collaborative organizational success. Conseque$\mathrm{n}$ tly, inadequate use of emotion could create ineffective decision-making and social conduct. In context, when rating subor- 
dinate job performance, a leader's inadequate use of emotion could create faulty evaluations.

\section{Job Performance}

Job performance comprised several dimensions pertinent to the study of emotional intelligence, including in-role (or task) performance and extra-role (or contextual/citizenship) performance (Côté \& Miners, 2006; Ng \& Feldman, 2008). Task performance refers to major substantive duties mandated, rewarded, and appraised by the employing organization (Côté \& Miners, 2006; Janssen \& Van Yperen, 2004). Contextual or citizenship performances refers to the extra behaviors not part of normal job duties, and are activities beyond major duties to aid in strengthening organizational effectiveness (Côté \& Miners, 2006; Johnson, 2005; Ng \& Feldman, 2008). Previous investigation has suggested that leaders take both task and contextual performance into consideration when evaluating performance (Podsakoff, MacKenzie, \& Hui, 1993).

\section{IT Leaders and EI}

Information technology leaders, who have built status based on technical expertise, often lack the adequate soft skills necessary to function when placed in complex situations that involve the management of people, resources, and strategy (Bernthal \& Wellins, 2006). Individuals with low emotional intelligence skills are likely to show ineffective reactions in situations involving interpersonal skills (Sen, 2008). One study conducted on information technology (IT) leaders identified the three predominant causes of leadership failure among technology managers: lack of empathy, lack of emotional ability, and the inability to connect with others (Caruso \& Gentry, 2005). This gives further support to the aforementioned proposition of Bernthal \& Wellins (2006) that many IT leaders lack the necessary soft skills and emotional abilities needed to have an effective impact on subordinates in the workplace.

\section{Methodology}

A quantitative, correlational approach was employed for this study by administering two validated quantitative instruments, the Emotional Quotient Inventory (EQ-i) and Van Scotter and Motowidlo's (1996) measure of contextual performance. Johnson (2001) contended that variables such as intelligence, aptitude, age, and job satisfaction, are not manipulable, and should be used in a correlational study. The EQ-i instrument was selected for measuring emotional intelligence because of its composition of emotional and socially intelligence behavior measures. The EQ-i is one of the longer-lived and most widely used instruments, and has been the focus of valuable validity studies (Bar-On, 1997; Dawda \& Hart, 2000).

Van Scotter and Motowidlo (1996) were instrumental in defining the construct of contextual performance and separating the concept into two facets: interpersonal facilitation and job dedication. The contextual performance measurement items developed by Van Scotter and Motowidlo (1996) were selected over Coleman and Borman's (2000) study because Coleman and Borman's (2000) items lacked an adequately valid and reliable scale to measure contextual performance behaviors. Van Scotter and Motowidlo's (1996) measures for contextual performance are divided into the two facets of interpersonal facilitation and job dedication.

\section{Sample}

The target population was information technology (IT) leaders within the Association for Information Technology Professionals (AITP) and the Information Technology (IT) Specialist LinkedIn group. The Association for Information Technology Professionals (AITP) selected for the study is one of the leading worldwide societies of information technology business professionals and is a community of knowledge for the current and next generation of leaders (AITP, 2010).

An e-mail message was sent by AITP headquarters to invite members to participate in the study. Instructions for completing the online survey were included in the e-mail message, as well as a hyperlink for accessing the online instrument. Qualifying participants were currently employed in various IT companies in the United States who were responsible for the conduction of formal performance appraisals of subordinates within their organization. Systematic sampling, in which every $n$th individual was selected, was employed because of the large number of possible participants available in the targeted professional groups. A sample of 72 participants was selected, a sample size appropriate for this correlational design (Creswell, 2005). Responses were analyzed using SPSS (17.0).

\section{Data Collection}

Participants completed two web-based instruments - the BarOn Emotional Quotient Inventory (EQ-i) and Van Scotter and Motowidlo's (1996) contextual performance measure. Demographic questions were included in the EQ-i instrument. The online survey instrument was hosted by SurveyMonkey, a free online survey software and questionnaire tool. Participants' responses were converted into Microsoft Excel spreadsheets and imported directly into SPSS 17.0 for analysis.

\section{Results}

Data analysis included descriptive statistics, Emotional Quotient Inventory Technical Manual, and Pearson Product-Moment Correlation. Of the 72 participants, $65.3 \%$ were female and $30.6 \%$ were male; the remaining $4.1 \%$ of the sample did not indicate their gender. The sample for this study ranged in age (26 to 66 years), with a mean participant age of 40.63 years.

An Emotional Quotient Inventory Technical Manual was used to determine IT leaders mean score; scale score interpretations can be viewed in Table 1. Descriptive statistics for the two job performance scales were presented in Table 2. The scores were based on a scale of one-to-five, with higher values reflecting more positive job performance. The results indicated that the subordinates in this study were rated as exhibiting interpersonal facilitation behaviors sometimes to regularly (3.80) and exhibiting job dedication behaviors sometimes to regularly (3.75). However, there was a wide range of scores indicating that some of the subordinates seldom or never exhibited such behaviors while others exhibited them very often.

As seen in Table 3, mean scores suggested that participants had an adequate degree of empathy, with an average score of 97.51. However, this was the area in which participants scored the lowest. Participants scored the highest on the independence subscale (106.68). Table 4 provided the descriptive statistics for each of the five EQ scales. Results indicated that, on average, participants scored highest on the stress management 
Table 1.

Emotional Quotient Subscale Interpretation Guide.

\begin{tabular}{cc}
\hline Standard score & Interpretive guideline \\
\hline $130+$ & Markedly high—atypically well developed emotional capacity \\
$120-129$ & Very high—extremely well developed emotional capacity \\
$110-119$ & High—well developed emotional capacity \\
$90-109$ & Average—adequate emotional capacity \\
$80-89$ & Low—under-developed emotional capacity \\
$70-79$ & Very low—extremely under-developed emotional capacity \\
Under 70 & Markedly low—atypically impaired emotional capacity \\
\hline
\end{tabular}

Table 2.

Job performance scale means and standard deviations.

\begin{tabular}{cccccc}
\hline Source & $\mathrm{N}$ & Minimum & Maximum & Mean & SD \\
\hline Interpersonal facilitation & 137 & 1.14 & 5.00 & 3.80 & 0.70 \\
Job dedication & 137 & 1.50 & 5.00 & 3.75 & 0.76 \\
\hline
\end{tabular}

Table 3.

Emotional intelligence subscale means and standard deviations.

\begin{tabular}{|c|c|c|c|c|c|}
\hline Source & $\mathrm{N}$ & Minimum & Maximum & Mean & SD \\
\hline Self regard & 72 & 77 & 128 & 103.79 & 11.27 \\
\hline Emotional self-awareness & 72 & 61 & 129 & 102.14 & 14.26 \\
\hline Assertiveness & 72 & 65 & 130 & 102.39 & 11.54 \\
\hline Independence & 72 & 75 & 122 & 106.68 & 11.20 \\
\hline Self actualization & 72 & 69 & 126 & 101.18 & 13.06 \\
\hline Empathy & 72 & 59 & 120 & 97.51 & 15.19 \\
\hline Social responsibility & 72 & 69 & 118 & 101.25 & 12.14 \\
\hline Interpersonal relationships & 72 & 71 & 127 & 100.46 & 13.70 \\
\hline Stress tolerance & 72 & 74 & 130 & 104.85 & 11.35 \\
\hline Impulse control & 72 & 78 & 131 & 104.51 & 12.22 \\
\hline Reality testing & 72 & 80 & 127 & 103.81 & 11.97 \\
\hline Flexibility & 72 & 74 & 131 & 104.83 & 13.17 \\
\hline Problem solving & 72 & 75 & 130 & 104.19 & 12.24 \\
\hline Optimism & 72 & 81 & 126 & 100.50 & 11.46 \\
\hline Happiness & 72 & 67 & 124 & 102.57 & 12.48 \\
\hline
\end{tabular}

scale (105.21), followed by the adaptability scale (105.08). Participants scored lowest on the interpersonal scale (100.08).

The Pearson correlation results between each of the 15 EQ subscales and the interpersonal facilitation scale were provided in Table 5. Results indicated that optimism has a weak correlation with interpersonal facilitation $(r=.24, p=.005)$. With a larger sample size the results could yield a stronger correlation. Self-actualization had a small effect on interpersonal facilita- tion, $r=.24, p=.005$, and a larger sample size of IT leaders and subordinates can strengthen the correlation of high emotional intelligence scores (IT leaders) with interpersonal facilitation scores (subordinates).

\section{Discussion}

This research study attempted to examine the notion that IT 
Table 4.

Emotional intelligence scale means and standard deviations.

\begin{tabular}{cccccc}
\hline Source & $N$ & Minimum & Maximum & Mean & $S D$ \\
\hline Intrapersonal & 72 & 73 & 129 & 104.11 & 11.55 \\
Interpersonal & 72 & 65 & 124 & 100.08 & 13.12 \\
Stress management & 72 & 77 & 128 & 105.21 & 10.87 \\
Adaptability & 72 & 82 & 131 & 105.08 & 11.81 \\
General mood & 72 & 74 & 128 & 101.50 & 11.26 \\
\hline
\end{tabular}

Table 5.

Pearson correlations between EQ subscales and interpersonal facilitation.

\begin{tabular}{cccc}
\hline & & Interpersonal facilitation & $p$ \\
Source & $N$ & $r$ & .372 \\
Self regard & 72 & .08 & .715 \\
Emotional self-awareness & 72 & -.03 & .890 \\
Assertiveness & 72 & .01 & .180 \\
Independence & 72 & .12 & .005 \\
Self actualization & 72 & .24 & .951 \\
Empathy & 72 & -.01 & .421 \\
Social responsibility & 72 & .07 & .546 \\
Interpersonal relationships & 72 &. .05 & .237 \\
Stress tolerance & 72 & .10 & .225 \\
Impulse control & 72 & .10 & .768 \\
Reality testing & 72 & .03 & .380 \\
Flexibility & 72 & .08 & .06 \\
Problem solving & 72 & .01 & .069 \\
Optimism & 72 & .914 \\
Happiness & 72 & & .005 \\
\hline
\end{tabular}

leaders failed in leadership roles due to a lack of empathy, a lack of emotional ability, and the inability to connect with others (Caruso \& Gentry, 2005). The purpose of this study was to investigate the relationship between IT leaders' emotional intelligence and subordinate contextual performance behaviors rat ings. IT leaders scored high on stress management and adapta-bility, and both of those leadership traits can be deemed as beneficial towards the development of empathy and the management of emotions and teammates. In the IT industry high demands are placed on management, and in turn, management might place those strains on their employees; this inability to manage stress can result in micromanaging of employees and poor performance throughout the organization. However, IT managers who focus on the management of emotions might be more effective than the highly skilled IT managers.

Technology firms are successful when they are structured with the most talented individuals. Some organizations might promote the highly skilled and knowledgeable workers, but the problem derives from poor leadership traits and qualities. Highly skilled IT employees do not guarantee highly skilled IT leaders, so IT firms should start investing in leadership programs that focus on the management of emotions and seek individuals that embody emotional intelligence. One could assume from this research that IT leaders with high emotional intelligence might be perceived as better performers in their job, but the weak correlations found cannot validate this notion. In this study, EI have proven high among IT leaders, so one could assume IT leaders displayed the ability to make rational and emotional decisions in regards to employee job ratings. Fair employee job ratings can inspire constituents to align their behaviors and actions to perform in a productive and successful manner.

\section{Conclusion}

This study supported previous assertions that optimistic leaders experience less stress and other negative emotions (Tan 
\& Tiong, 2005), which may allow the leaders to effectively rate subordinates contextual performance behaviors. Results also suggest that IT leaders who possess the EI skill of self-actualization are aware of and can positively rate subordinates' display of cooperative, considerate, and helpful acts that create interpersonal facilitation. The current research demonstrated the existence of a relationship between leaders EI and subordinates job performance. Findings can be interpreted to mean that higher levels of leader EI have a positive relationship with how leaders rate subordinates' display of acts beyond normal job duties.

Understanding the specific relationship between leaders' EI and subordinate job performance may help leaders decide on performance approaches with subordinates to support organizational effectiveness. Future studies can be used to explore the benefits of EI on other leaders across a broad spectrum of industries. Additionally, it is recommended that future investigation examine EI inventory scores of male managers versus female managers and how those scores can impact their job evaluation performance. Finally, a larger sample size should be examined to offer stronger and more generalizable findings

\section{REFERENCES}

Amazon (2010a). Emotional intelligence. URL (last checked 15 October 2010).

$\mathrm{http}: / /$ www.amazon.com/s/ref=nb_sb_noss?url=search-alias\%3Dstrip books\&field-keywords $=$ emotional + intelligence $\& x=4 \& y=20$

Association for Information Technology Professionals (AITP) (2010). About AITP. URL (last checked 12 November 2010).

http://www.aitp.org/organization/about/mission/mission.jsp

Bar-On, R. (1997). The emotional quotient inventory (EQ-i): A test of emotional intelligence. Toronto: Multi-Health Systems.

Bernthal, P., \& Wellins, R. (2006). Trends in leader development and succession. Human Resource Planning, 29, 31-40.

Caruso, D. R., \& Gentry, K. F. (2005). Why leadership fails. Business-IT Strategies Executive Update, 8, 1-3.

Coleman, V. I., \& Borman, W. C. (2000). Investigating the underlying structure of the citizenship performance domain. Human Resource Management Review, 10, 25-44. doi:10.1016/S1053-4822(99)00037-6

Cooper, R. K. (1997). Applying emotional intelligence in the workplace. Training \& Development, 51, 31-38.

Côté, S., \& Miners, C. T. H. (2006). Emotional intelligence, cognitive intelligence, and job performance. Administrative Science Quarterly, 51, 1-28.

Creswell, J. (2005). Educational research: Planning, conducting and evaluating quantitative and qualitative research ( $2 \mathrm{nd}$ ed.). Upper Saddle River, NJ: Merrill Prentice-Hall.

Daus, C. S., \& Ashkanasy, N. M. (2005). The case for an ability-based model of emotional intelligence in organizational behavior. Journal of Organizational Behavior, 26, 453-466. doi:10.1002/job.321

Dawda, D., \& Hart, S. D. (2000). Assessing emotional intelligence: Reliability and validity of the Bar-On emotional quotient inventory (EQ-i) in university students. Personality and Individual Differences,
28, 797-812. doi:10.1016/S0191-8869(99)00139-7

Fambrough, M. J., \& Hart, R. K. (2008). Emotions in leadership development: A critique of emotional intelligence. Advances in Developing Human Resources, 10, 740-758. doi: $10.1177 / 1523422308323542$

Field, A. (2009). Discovering statistics using SPSS (3rd ed.). Los Angelos, CA: Sage.

George, J. M. (2000). Emotions and leadership: The role of emotional intelligence. Human Relations, 53, 1027-1055. doi: $10.1177 / 0018726700538001$

Janssen, O., \& Van Yperen, N. W. (2004). Employees' goal orientations, the quality leader-member exchange, and the outcomes of job performance and job satisfaction. Academy of Management Journal, 47, 368-384. doi: $10.2307 / 20159587$

Johnson, B. (2001). Toward a new classification of nonexperimental quantitative research. Educational Researcher, 30, 3-13. doi:10.3102/0013189X030002003

Johnson, V. (2005). Emotional intelligence: Are successful leaders born or made? The Business Review, Cambridge, 3, 21-26.

Law, K. S., Wong, C., Huang, G., \& Li, X. (2008). The effects of emotional intelligence on job performance and life satisfaction for the research and development scientist in China. Asia Pacific Journal of Management, 25, 51-69. doi:10.1007/s10490-007-9062-3

Mahoney, K. (2007). Solid skills make a solid employee. Inside Tucson Business. URL (last checked 25 June 2010). http://www.azbiz.com

Mayer, J. D., \& Salovey, P. (1997). What is emotional intelligence? In P. Salovey, \& D. Sluyter (Eds.), Emotional development and emotional intelligence: Educational implications (pp. 3-31). New York: Basic Books.

Morehouse, M. M. (2007). An exploration of emotional intelligence across career arenas. Leadership \& Organization Development, 28, 296-307. doi:10.1108/01437730710752184

Ng, T. W. H., \& Feldman, D. C. (2008). The relationship of age to ten dimensions of job performance. Journal of Applied Psychology, 93, 392-423. doi:10.1037/0021-9010.93.2.392

Pinos, V., Twigg, N. W., Parayitam, S., \& Olson, B. J. (2006). Leadership in the 21st century: The effect of emotional intelligence. Academy of Strategic Management Journal, 5, 61-74.

Podsakoff, P. M., MacKenzie, S. B., \& Hui, C. (1993). Organizational citizenship behaviors and managerial evaluation of employees' performance: A review and suggestions for future research. In G. R. Ferris (Ed.), Research in personnel and human resources management (Vol. 11, pp. 1-40). Greenwich, CT: JAI Press.

Sen, S. (2008). Interpersonal skills through emotional intelligence: A psychological perspective. The Icfai University Journal of Soft Skills, 2, 25-30.

Smith, H., \& McKeen, J. D. (2005). Developments in practice XIX: Building better IT leaders from the bottom up. Communications of the Association for Information Systems, 16, 785-795.

Tan, V., \& Tiong, T. N. (2005). Change management in times of economic uncertainty. Singapore Management Review, 27, 49-68.

Van Scotter, J. R., \& Motowidlo, S. J. (1996). Interpersonal facilitation and job dedication as separate facets of contextual performance. Journal of Applied Psychology, 81, 525-531. doi:10.1037/0021-9010.81.5.525

Wong, C., \& Law, K. (2002). The effects of leader and follower emotional intelligence on performance and attitude: An exploratory study. The Leadership Quarterly, 13, 243-274. doi:10.1016/S1048-9843(02)00099-1 